\title{
Web-Based Geographic Information System for UWRSR Evaluations
}

\author{
W. H. Zeng ${ }^{*}$, Y. J. Zhang, J. L. Liu, and Z. F. Yang \\ School of Environment, Beijing Normal University, State Key Laboratory of Environmental Simulation and Pollution Control, \\ Beijing 100875, P. R. China
}

\begin{abstract}
The concept of Urban Water Resource Social Renewability (UWRSR) was proposed in this paper to evaluate water resource conditions from the perspective of social economic. The evaluation index system was set up and is composed of such four categories as urban infrastructure, industrial water consumption, daily life water consumption, and agricultural and landscape water consumption. A mathematic model of UWRSR evaluation based on artificial neural network was further developed, based on which the main cities in the Yellow River basin were evaluated. Also the Web-based Geographic Information System was constructed, and the results of evaluation were published via internet. The limitations of the municipal water management could be identified through UWRSR evaluation, which in turn will benefit policy makers to make decisions on the utilization and development of urban water resources for the future. Also the system will provide an opportunity for the public to be acquainted with the UWRSR status and facilitate related research by offering data support.
\end{abstract}

Keywords: artificial neural network, regeneration of water resources, water resource social renewability, water resource renewability, web-based geographic information system, Yellow River basin

\section{Introduction}

As a dynamic system, urban water resource could act as a dependent variable of a collection of factors including climatology, hydrology, the capabilities of water supply and drainage system, population, citizen living conditions, economic development levels of the city and industrial structure (Hong et al., 2000). The situations of urban water resource should be evaluated based on the natural characteristic such as water quality and quantity. Besides, the evaluation should be conducted from the social economic perspective, namely the utilization, allocation, management of water resource.

A completely new method of water resource evaluation, by using the social renewability as the core, urban water resource social renewability (UWRSR) was proposed and caculated in the context of Yellow river case in this paper. Previous evaluation methods were mostly based on the natural circulation of water, and ignored social circulation. Even the evaluation in particular for the urban water resources mostly centered around the natural conditions of water resource $\mathrm{Xu}$, 1997; Peng et al., 2000). Putting an emphasis on the social renewability can better reveal the potential of the utilization of urban water resource, and pertinently discover the shortcoming of urban water resource management work by analyzing various departments of urban water regeneration, so as to offer constructive suggestions to urban water utilization planning.

At the present time, Internet has evolved into such an

\footnotetext{
* Corresponding author: zengwh@bnu.edu.cn
}

important communication media that it has quickly become a leading factor in the development of Geographic Information System (GIS) technology (Thoen, 1999). With the rapid development of GIS over the past two decades, Web-based GIS has emerged and geographic visualization tools for dealing with spatial data are available over the Internet (El-Raey et al., 2000; Huang and Lin, 1999; Peng and Tsou, 2003). Web-GIS provide much more access opportunities for users to investigate spatial and non-spatial data as well as carry out spatial analysis by engaging Browser/Server architecture. User (client) submits quests that will be processed by the web server, and then a result will be delivered to the client side by means of updating map in a Web browser window (Halls, 2003). In a Web-GIS application, it becomes possible for users to navigate exiting spatial objects(e.g. points, lines) and/or other related attribute information via the Web browser (Park, 2001) with ease. In public participation of environment management, Web-GIS has been used as a tool to facilitates the communication among different interest groups like planners, decision makers and citizens and help decision makers to draw a conclusion (Sarjakoski, 1998; Sieber, 2006).

Based on UWRSR evaluation of major cities in Yellow River drainage area, a corresponding information publishing system was established in this paper by taking advantage of Web-GIS technology, through which users could have access to the results. In light of urban water resource renewability evaluation and the results analysis, we can identify shortcomings of the municipal water management. As such, it will be helpful for the policy makers to make decisions on the utilization and development of water resource for the future. The rest of this paper is set out as follows. 


\section{The Concept of Urban Water Resources Social Renewability (UWRSR)}

As a basic characteristic of water resource, regeneration means that the water resource can be constantly supplemented by means of reutilization in some circulations, and makes it possible that the amount of actual utilized water could be larger than the total input in a circulation system (Zeng et al., 2001). Social regeneration of water resource refers to the process in which water obtains utilization values again resulting from human beings interference actions. The regained utilization value could be measured by introducing the concept of water resource readability. The concept emphasizes the reutilization of water resource within social system and the reoccurrence of its value. To understand this, we should pay attention to the three points as follows: human activities, urban space scope and interior reutilization.

Water resource renewability refers to the renewable amount of water resource in some existing form per time unit on the condition of certain geographic space, certain functional structure of water environment and technical and economic level. It can be measured by the renewable amount of water resource:

$$
q(t)=Q(t) / T
$$

where $q$ is water resource renewability, $Q$ is the storage amount of water resource, and $T$ is the renewable cycle of water resource.

Water resource renewability consists of two parts: natural renewability and social renewability. The natural renewability depends on the natural circulation of water resource. Water resource can be continuously renewed, supplemented in 'quantity' through evaporation, precipitation, and runoff and in 'quality' by self-purified. As such, the natural renewability of water resource refers to both 'quantity' and 'quality' regeneration.

The other part of water resource renewability is the social renewability (or called 'artificial renewability'). From the perspective of water resource social circulation, the quality of water resource has been declining continuously due to human's constant exploitation and utilization. The resulting loss of water resource could be compensated by natural regen-

Table 1. Hierarchy of Index System of Water Resources Renewability Assessment

\begin{tabular}{|c|c|c|c|}
\hline \multirow[t]{8}{*}{$\begin{array}{l}\text { Index system } \\
\text { of water } \\
\text { resources' } \\
\text { renewable } \\
\text { capacity } \\
\text { assessment }\end{array}$} & \multirow[t]{4}{*}{$\begin{array}{l}\text { Indices of urban water } \\
\text { resources' regenerated } \\
\text { amount assessment }\end{array}$} & $\begin{array}{l}\text { Urban } \\
\text { infrastructure }\end{array}$ & $\begin{array}{l}\text { GNP (in 10,000 yuan) } \\
\text { The level of city management } \\
\text { The capacity of wastewater treatment (ton per day) } \\
\text { The capacity of reservoir (in } 100 \text { million tons) }\end{array}$ \\
\hline & & $\begin{array}{l}\text { Industrial } \\
\text { water } \\
\text { consumption }\end{array}$ & $\begin{array}{l}\text { The discharging amount up to par of industrial wastewater （in 10,000 tons) } \\
\text { The reusing amount of treated industrial wastewater (in } 10,000 \text { tons) } \\
\text { The investment on treating wastewater (in 10,000 yuan) }\end{array}$ \\
\hline & & $\begin{array}{l}\text { Daily life } \\
\text { water } \\
\text { consumption }\end{array}$ & The price of water consumed in daily life(in yuan per ton) \\
\hline & & $\begin{array}{l}\text { Agricultural } \\
\text { and landscape } \\
\text { water } \\
\text { consumption }\end{array}$ & $\begin{array}{l}\text { The area of gardens and virescence (ha.) } \\
\text { Efficient irrigating area (ha.) }\end{array}$ \\
\hline & \multirow[t]{4}{*}{$\begin{array}{l}\text { Indices of urban water } \\
\text { resources' } \\
\text { regeneration } \\
\text { efficiency assessment }\end{array}$} & $\begin{array}{l}\text { Urban } \\
\text { infrastructure }\end{array}$ & $\begin{array}{l}\text { GNP per person（in } 10,000 \text { yuan }) \\
\text { Payout of education per person (yuan) } \\
\text { The density of drainage pipeline ( } \mathrm{km} . / \mathrm{sq} . \mathrm{km} .) \\
\text { The cost of water in sale per unit (yuan/1,000 tons) }\end{array}$ \\
\hline & & $\begin{array}{l}\text { Industrial } \\
\text { water } \\
\text { consumption }\end{array}$ & $\begin{array}{l}\text { The percentage of discharged industrial wastewater up to par }(\%) \\
\text { The percentage of reusing industrial wastewater (the reusing amount: the treated } \\
\text { amount) } \\
\text { The strength of investment on treating wastewater(the invested quantum/GNP) }\end{array}$ \\
\hline & & $\begin{array}{l}\text { Daily life } \\
\text { water } \\
\text { consumption }\end{array}$ & $\begin{array}{l}\text { Daily life water consumption per person(ton) } \\
\text { Laborage level per thousand tons of water (yuan/1,000 tons) } \\
\text { The percentage of popularization of urban water supply ( } \%)\end{array}$ \\
\hline & & $\begin{array}{l}\text { Agricultural } \\
\text { and landscape } \\
\text { water } \\
\text { consumption }\end{array}$ & $\begin{array}{l}\text { The percentage of area covered with virescence }(\%) \\
\text { The water consumption per } 10,000 \text { yuan agricultral production value } \\
\text { (tons } / 10,000 \text { yuan) }\end{array}$ \\
\hline
\end{tabular}




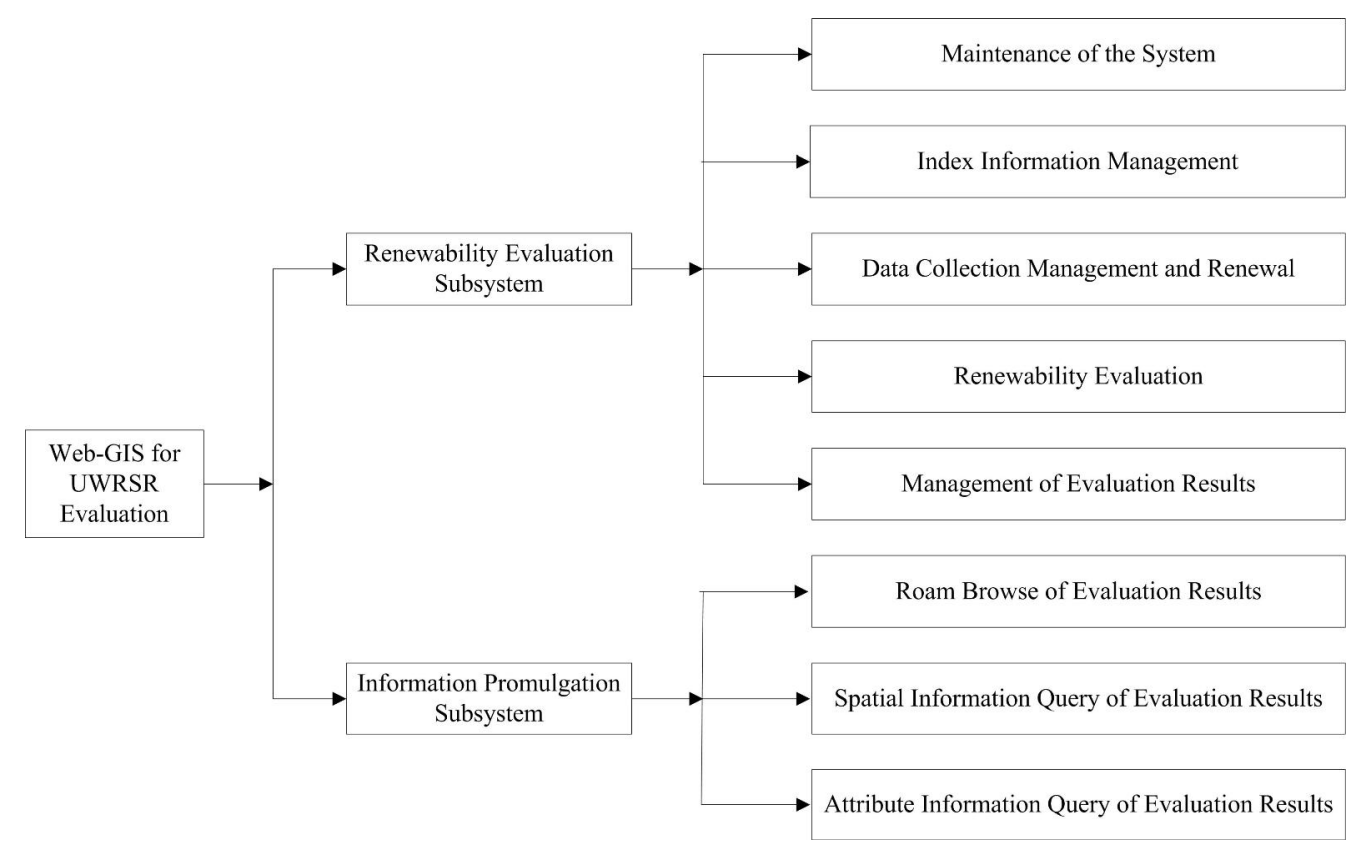

Figure 1. Architecture of the web-based geographic information system for UWRSR evaluation of main cities in the Yellow River basin.

eration (self-purification) on the one hand, and by artificial treatment on the other hand. Such a process of wastewater reclamation is known as the social renewability of water resource. And the one that happens in urban areas could be called urban water resource social renewability (UWRSR).

Water circulation becomes more complicated due to the introduction of UWRSR, but at the same time the efficiency of water utilization and its actual amount have consequently been increased. UWRSR can be explained from two aspects, namely absolute renewability and relative renewability. The total amount of urban water social regeneration is called absolute renewability, which is closely related to city scale and natural conditions. The absolute renewability reflects the absolute quantity of socially-regenerated water to some extent. Relative renewability primarily indicates the regeneration efficiency of UWRSR, that is, UWRSR is considered based on the city's comprehensive competence regardless of the scale of city to make it possible that different cities can be compared. The relative water renewability, which is relevant to the development level of the city, the awareness of environmental protection as well as the investment strength of related projects, manifests this city's present water situations and potentials of water resource renewability in some sense.

Table 1 shows the hierarchy of index system of water resource renewability assessment which oculd be divided into two categories. The absolute renewability evaluation indices possess measurement units based on which the evaluation result could indicate the total amount of regenerated water resource. The relative renewability indices consist of rate type data with no units and ratio data with units, and the corres- ponding evaluation result could demonstrate the level of urban water management and renewable potentials. Indices of each set can be composed of four parts: indices of urban infrastructure, industrial water consumption, daily life water consumption and agricultural and landscape water consumption.

\section{Web-GIS Based Information Promulgation System for UWRSR Evaluation}

\subsection{Systemic Design}

The information promulgation system of UWRSR evaluation for main cities in Yellow River basin consists of two subsystems, the evaluation subsystem and the information promulgation subsystem (Shown in Figure 1). The former one centers on data maintenance, establishment and training of the Artificial Neutral Network (ANN), UWRSR evaluation and the management of the evaluation results. The later subsystem primarily focuses on the information promulgation via the Internet by using web-GIS technology.

The information promulgation subsystem is a Web-GIS system with standard Browser/Server structure (shown in Figure 2). There are three kinds of servers altogether in this system: Web server is responsible for www service; application server is in charge of managing users' requests and complicated spatial analysis and data server takes care data storage and management. Users can have access to the system with Internet Explorer or other browsers. Program and data can be downloaded to the local side through which users can navigate maps, query data and make theme maps. We can 
construct the communication between spatial data, embedded as java applet, and HTML web pages by invoking the methods, attributes and events of Applet through JavaScript. Data exchange between browser and server was implemented by using ASP to manipulate database based ADO groupware. Through the identical ID, geographic information and of UWRSR evaluation results are connected. As such users could conduct bidirectional query between spatial data and nonspatial attribute data. They could identify the UWRSR situations of interested areas and make theme maps such as bar charts and choropleth maps.

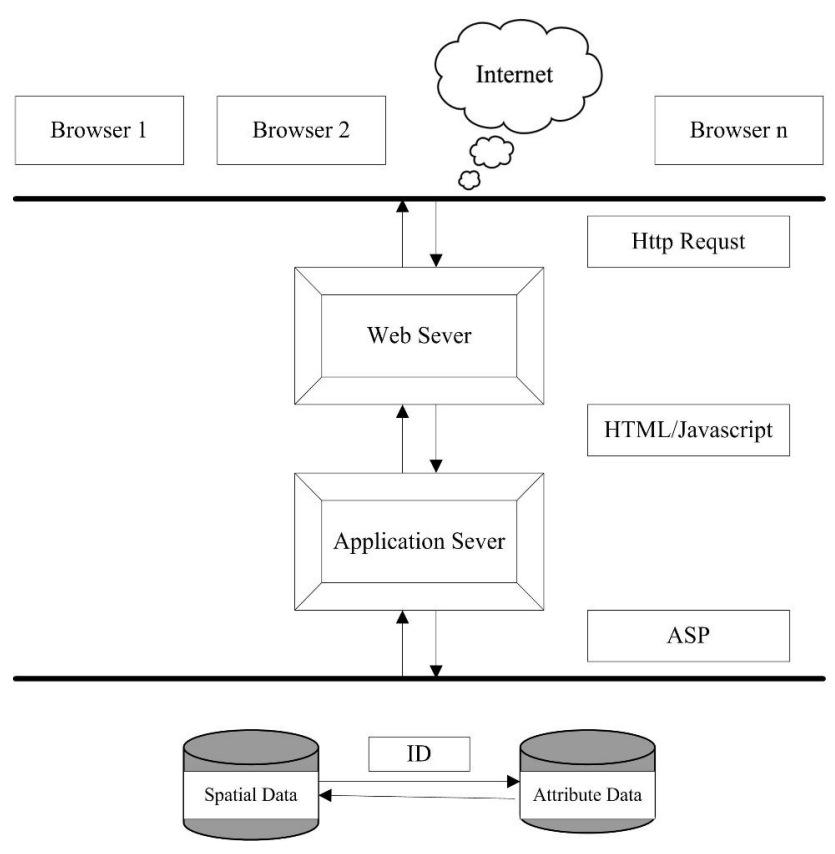

Figure 2. Framework of the web-based geographic information system for UWRSR evaluation of main cities in the Yellow River basin.

\subsection{The Evaluation Model of UWRSR Based on Artificial Neural Network (ANN)}

3.2.1. The Establishment of Evaluation Standard and Training Samples

As an important branch of AI, Artificial Neural Network (ANN) was brought forward in the middle-late 1980s. It is a kind of engineering system that stimulates the structure and intelligent behaviors of human brain based on the understanding of human brain's organizational structure and functional mechanism. Nowadays ANN has been designed to perform complex functions in various fields of application including pattern recognition, identification, classification, speech, vision and control systems. To establish ANN, the first setp is to create training samples. The evaluation standards set by ourselves are adopted as training samples. During this procedure, the concept of virtual city was introduced in this paper. That is to say, we obtain the maximum and minimum values of the indices mentioned above first, and then get a city A, which is set as the highest level (5) with the maximum value of indices. In the same manner we get a city $\mathrm{B}$, which is set as the lowest level $(0)$ with the minimum value of indices. Thus, we get cities ranging from six levels $(0,1,2$, 3,4 , and 5). In this way, the evaluation has been converted to classification problem that can be solved by ANN with ease.

\subsubsection{The Establishment of the Model}

Since the birth of ANN, a large amount of network models and study algorithm have been put forward and every algorithm has its own application field (Wang et al., 2000). The back propagation (BP) algorithm was adopted in this paper.

In the architecture of BP artificial neural network, two or more neurons can be combined in a layer, and a particular network could contain one or more such layers. The model presented in this paper was built based on multiple-layer feed forward BP network, which is founded on the algorithm of error back propagation (Yang, 2001). The BP network used in this paper consists of three layers: input layer, single hidden layer and output layer (shown in Figure 3).

The first step in training a feed forward BP network is to create the network and initialize the weights and threshold quantity. Then the input vector is transferred to the hidden layer and goes to the output layer after being calculated by some transfer functions. In this case, Sigmoid functions (Equations (2) and (3)) were chosen as the transfer functions. Through the calculation of transfer functions we get the output vector, and compare the actual output to the desired output. If the error is bigger than the threshold we set in advance, the back propagation begins. During the process of back propagation, the weights will be amended. Such procedure will be repeated and won't stop until we get satisfactory results.

$$
\begin{aligned}
& Y_{i}=f\left(\sum_{j=1}^{N} u_{j} \times W_{i j}+\theta_{i}\right) \\
& f(x)=\frac{1}{1+e^{\frac{-x}{u_{0}}}}
\end{aligned}
$$

where $f(x)$-- Sigmoid stimulated function; $Y_{i}$-- output value of each unit; $U_{i}$-- input value of each unit; $W_{i j}$-- the connecting proportion value with previous layers; $\theta_{i}$-threshold proportion value; $N$-- the number of previous layers.

\section{UWRSR Evaluation for Main Cities in the Yellow River Basin Using the System}

The Yellow River, known as the "cradle of the Chinese civilization", is the second longest river in China with a flowing course about $5,464 \mathrm{~km}$. The drainage area of the river 


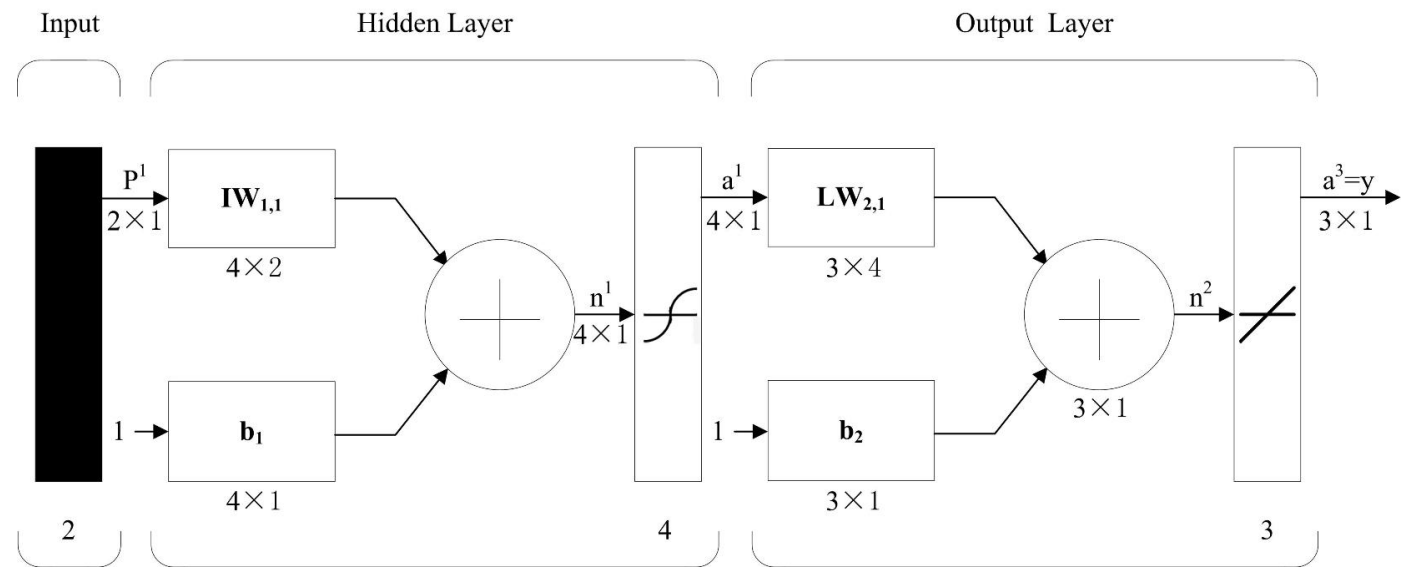

Figure 3. BP Neural Network with a single hidden layer.

reach $75.2 \times 10^{4} \mathrm{~km}^{2}$, the total area is $79.5 \times 10^{4} \mathrm{~km}^{2}$, and the total population within the drainage basin amounts to 290.37 million with an arable land area of 13 million $\mathrm{km}^{2}$. In recent years, human activities have imposed great impacts on the water resource of the Yellow River. The influences are mainly from two aspects. First of all, the amount of water consumption within the drainage area together with water transfered to outside the basin have constantly increased, which has directly caused the measured runoff reduction in each control section of the river. Secondly, all sorts of hydraulic engineering and bioengineering porjects have changed the condition of underlying surface, which has reduced the amount of water naturally-yielded accordingly. The water demand, however, has been increasing tremendously as the population booms and economy rapidly develops. Moreover, the environmental pollution of water has severely aggravated. Thus, the conflict between water demand and water supply has come into sight and become the major environment problem of the Yellow River basin, especially in some big cities.

To address the conflict of water demand and supply, we must first get an understanding of the UWRSR of these cities. Therefore, this paper employs Artificial Neural Network and conventional Gray Associating Analytic Method to evaluate the UWRSR of main cities in the Yellow River drainage area respectively. The evaluation results of UWRSR for main cities in the Yellow River basin could be seen from Figure 4 and the exact numbers are listed in Table 2.Basically, the absolute renewability is relatively low compared with other cities in China, which agree with the water shortage situation in this basin. Only a few of them such as Jinan and Zhengzhou could reach the medium level. From the table it is also shown that the relative renewabiligy scores are a little higher than that of absolute one, although they are still not that high from the national level. It is not hard to understand such status quo from the perspective of great water shortage in the basin. The relative renewability mainly stands for the water management level. Though there is a lack of water in these cities, most of them have paid enough attention to the related management work for the better utilization of water resource. What's more, it can also be seen that provincial capitals do a better job than other cities, which reflects their better competence in some sense. Jinan, Zhengzhou and Xi'an have higher Water Resource Social Regenerated Amount and Efficiency. Relative and absolute renewability of Jinan scored 2.6 and 2.4 which ranked No. 1 in the basin and equals to the medium level of the national standards established on the basis of "Virtual Cities' proposed in the evaluation method by using ANN. Due to poorer natural conditions and slower urban developing speed, the UWRSR of other provincial capitals such as Huhhot, Lanzhou, Xining, Yinchuan and Taiyuan is comparatively lower. Other cities like Baotou, Kaifeng, Luoyang which aren't paid so much attention to as the provincial capitals have much lower UWRSR.

Table 2. UWRSR Evaluation Results of Main Cities in the Yellow River Basin in 2000

\begin{tabular}{lllll}
\hline \multirow{2}{*}{ Cities } & \multicolumn{2}{l}{ Absolute Renewability } & \multicolumn{2}{l}{ Relative Renewability } \\
\cline { 2 - 5 } & Results & Grade & Results & Grade \\
\hline Taiyuan & 0.73926 & 0.7 & 2.4755 & 2.5 \\
Jinan & 2.5502 & 2.6 & 2.4446 & 2.4 \\
Dongying & 0.011036 & 0 & 2.0645 & 2.1 \\
Zhengzhou & 2.3044 & 2.3 & 1.9942 & 2.0 \\
Kaifeng & 0.091814 & 0.1 & 1.3097 & 1.3 \\
Luoyang & 0.66488 & 0.7 & 1.0632 & 1.1 \\
Xinxiang & 0.60951 & 0.6 & 1.0542 & 1.1 \\
Xi'an & 2.1784 & 2.2 & 1.5346 & 1.5 \\
Baoji & 0.4522 & 0.5 & 1.2238 & 1.2 \\
Xianyang & 0.51197 & 0.5 & 0.78939 & 0.8 \\
Xining & 1.654 & 1.7 & 1.2761 & 1.3 \\
Huhehaote & 1.3353 & 1.3 & 1.4664 & 1.5 \\
Baotou & 0.46766 & 0.5 & 1.4036 & 1.4 \\
Lanzhou & 1.2069 & 1.2 & 1.8079 & 1.8 \\
Yinchuan & 1.4964 & 1.5 & 1.6287 & 1.6 \\
\hline
\end{tabular}




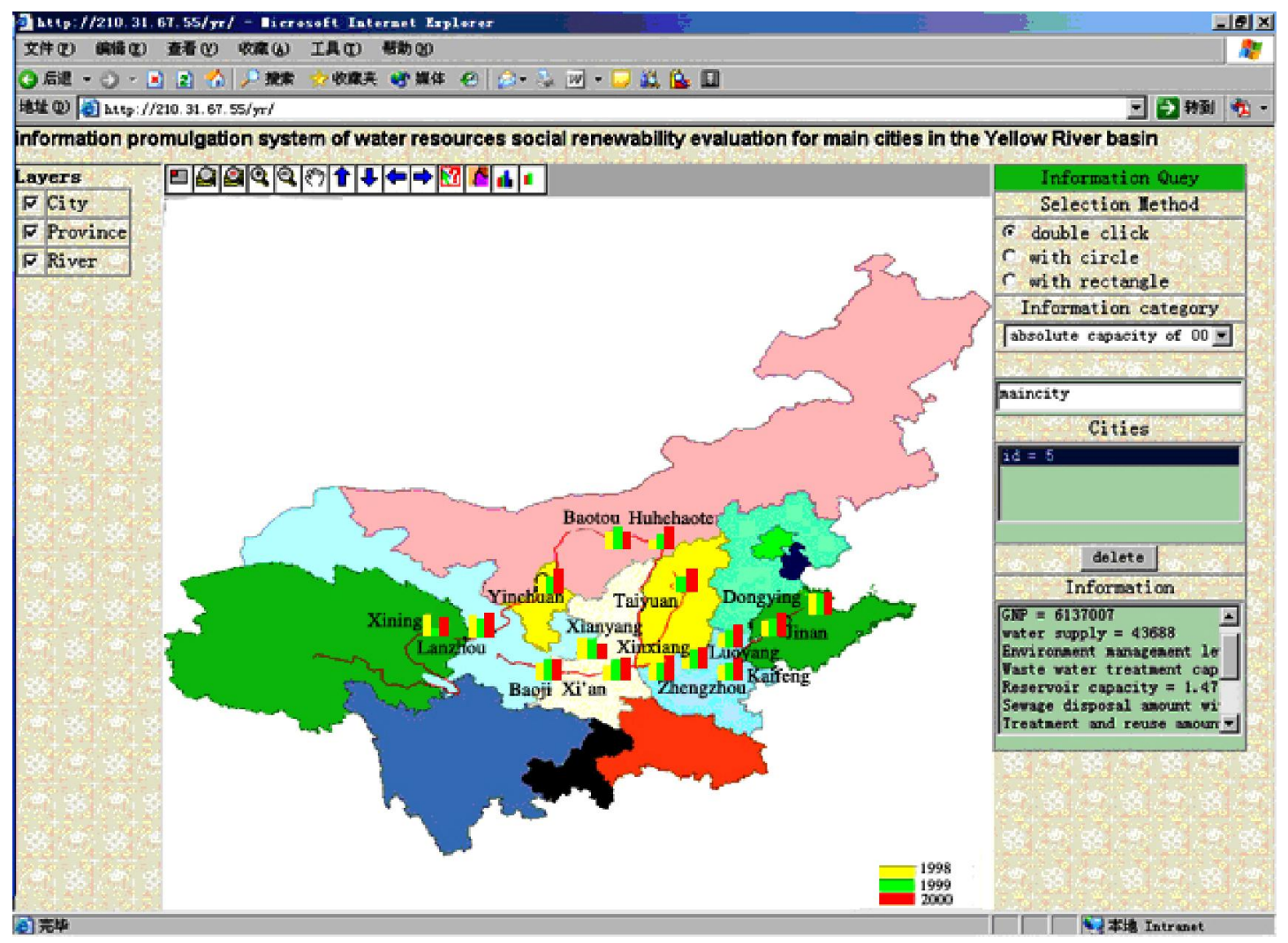

Figure 4. Thematic map of UWRSR evaluation for main cities in the Yellow River basin in 2000.

Figure 4 is a thematic map generated by the Web-based Geographic Information System for UWRSR evaluation. From this map, users could identify the variation of scores between different cities as well as the temporal change tendency.

\section{Discussion}

Based on the concept of UWRSR, Social Renewability Evaluation Indices System was established in this paper. ANN and conventional Gray Associating Analytic Method were employed to develop the evaluation models. By the comparison of methods, it could be argued that the ANN method has many advantages over the conventioal ones. Firstly, the acquirement of proportion values was based on the learning process by means of combining standard training samples constructed based on 'Virtual Cities'. Therefore, the results become much more objective due to the deprivation of subjective impact. This is what the conventional evaluation methods cannot do, and other methods mostly need to select parameters and adjust proportion values according to different instances. The maximum and minimum values are used to be the standards of two extreme 'virtual cities', highest and lowest levels the sores of which are 5 and 0 respectively. The intermediate levels are divided based on the range and a series of virtual cities are generated as the training samples of the
BP network. Secondly, constructing training samples based on 'Virtual Cities' can on the one hand solve the problem of selecting training samples, and endow the evaluation results with actual connotations to make them more intuitionistic and intelligible on the other hand. Finally, compared with previous evaluation methods of urban water resource, the ANN method makes the evaluation simple and convenient for calculation.

The UWRSR evaluation for main cities in the Yellow River basin were conducted based on the data of year 1998, 1999 and 2000 in this paper. The evaluation result, which points out that the UWRSR of main cities in the Yellow River basin is at large on the low level, is consistent with the water resource status quo of the area, decreased water supply and increasing water demand. The low absolute renewability indicates the shortage of water in the whole basin, especially in some hinterland cities. The relative renewability is not high either because most of the cities are less developed. And the water management remains at low level. Among these cities, we can find that provincial capitals score higher especially in terms of regenerated efficiency. It also complies with the economic strength and comprehensive competence of these cities. Thus, it could be argued that the UWRSR has a close relationship with city's development level and economic. Although the score of some cities is low in 2000, situations have been becoming better and better and the upward tendency is evident. 
Through analysis of the evaluation results together with the original data, we can identify the merits as well as limitations of the municipal work and propose constructive suggestions to the local government. The corresponding departments could improve water resource management based on the local UWRSR situations. In the cities with lower absolute regenerated amount, efforts should be made to advance the capability of exploring new water sources and the ones that can be reused according to local situations. When it comes to the cities with lower regenerated efficiency, emphasis should be put on the improvement of water management. As to the specific index, efforts should be made to address the specific problems. For instance, Xianyang scores lowest in UWRSR, resulting from the lower values of two indices, the density of drainage pipeline and the amount of investment in treating waste water. This indicates that Xianyang's infrastructure construction and investment strength of environmental protection need to be enhanced.

\section{Conclusions}

Eventually, the Web-based Geographic Information system for UWRSR evaluation of main cities in the Yellow River basin was set up in this research. Users at different locations can have access to the system and query the information they care for such as basic data, environmental data and the results of the evaluation etc., and make theme maps such as choropleth map and bar chart via the Internet. Futhermore the information could be updated and published real-time. In this way, the establishment of this system will enable the citizens to be acquainted with the UWRSR status, provides data support for research institutions and offers decision support to government as well.

Acknowledgments. This study is funded by the National Natural Science Fund of China (70273005) and the National key basic research and development plan projects (2006CB403403).

\section{References}

El-Raey, M., Fouda, Y. and Gal, P. (2000). GIS for environmental assessment of the impacts of urban encroachment on Rosetta Region. Egypt Environ. Monit. Assess., 60, 217-233.

Hong, Y. and Cao, J. (2000). Primary study on urban water resources index system of comprehensive assessment. Shanghai Environ. Sci., 19(6), 269-271.

Huang, B. and Lin, H. (1999). GeoVR: A web-based tool for virtual reality presentation from 2D GIS data. Comput. Geosci., 25, 1167-1175.

Park, D.-J. and Kim, H.-J. (2001). Prefectch policies for large objects in a Web-enabled GIS application. Data knowl. Eng., 37, 65-84.

Peng, Z.R. and Tsou, M.H. (2003). Internet GIS: Distributed Geographic Information Services for the Internet and Wireless Networks, John Wiley \& Sons, NJ.

Halls, J.N. (2003). River run: An interactive GIS and dynamic graphing website for decision support and exploratory data analysis of water quality parameters of the lower Cape Fear river. Environ. Model. Softw., 18, 513-520.

Peng, Y.H., Yang, Z.J. and Wang, S.L. (2000). A discussion on the method of water resources assessment for planning. Geol. Anhui, 10(2), 138-141.

Sieber, R. (2006). Public participation Geographic Information Systems: A literature review and framework. Ann. Assoc. Am. Geogr., 96(3), 491-507.

Sarjakoski, T. (1998). Networked GIS for public participation emphasis on utilizing image data. Comput. Environ. Urban Syst., 22(4), 381-392.

Thoen, B. (1999). GIS online: How has the Internet influenced GIS. GEOWorld, 12(2), 32-33.

Wang, X., Wang, H. and Wang, W.H. (2000). Theory and Application of $A N N$, Northeastern University Press.

$\mathrm{Xu}$, C.Y. (1997). Application of water balance models to different climatic regions in China for water resources assessment. Water Resour. Manage., 11(1), 51-67.

Yang, Z.H. (2001). Safety preliminary evaluation method based on neural network theory. Gold., 22(11), 12-15.

Zeng, W.H., Yang, Z.F. and Jiang, Y. (2001). Principium of reproduccible ability of water resources. Adv. water Sci., 12(2), 276-279. 